\title{
Predicting suitable release sites for assisted colonisations: a case study of eastern barred bandicoots
}

\author{
Anthony R. Rendall ${ }^{1, *}$, Amy L. Coetsee ${ }^{2}$, Duncan R. Sutherland ${ }^{1}$ \\ ${ }^{1}$ Research Department, Phillip Island Nature Parks, Cowes, 3922 Victoria, Australia \\ ${ }^{2}$ Wildlife Conservation and Science, Zoos Victoria, Elliott Avenue, Parkville, 3052 Victoria, Australia
}

\begin{abstract}
Assisted colonisations are increasingly being used to recover endangered or functionally extinct species. High quality habitat at release sites is known to improve the success of assisted colonisations, but defining high quality habitat can be challenging when species no longer inhabit their historical range. A partial solution to this problem is to quantify habitat use at release sites, and use results to inform assisted colonisation in the future. In this study, we quantified habitat use by the eastern barred bandicoot Perameles gunnii, functionally extinct on the Australian mainland, immediately after translocation to an island ecosystem. The release site, Churchill Island in Westernport, Victoria, Australia, has a mix of open woodlands and open pasture, providing a range of habitat conditions considered appropriate for nesting and foraging. A total of 16 bandicoots were radio-tracked for $30 \mathrm{~d}$ immediately post-release. Early survivorship was high (94\%), with males found to have larger home ranges and move greater distances from their first nest than females. Males and females initially used structurally complex habitats for nesting and foraging; as they became more established, males moved further from their release point and both sexes increased their use of open habitats during nightly activity. Female home ranges had limited overlap, suggesting intra-sexual territoriality. Males exhibited larger overlapping home ranges. Our results assist in quantifying habitat use of bandicoots immediately postrelease and will be used to inform future assisted colonisations of the species to larger islands, in the presence of feral cats.
\end{abstract}

KEY WORDS: Assisted colonization · Island conservation · Endangered species

\section{INTRODUCTION}

Assisted colonisations are the intentional movement and release of organisms outside their indigenous range to avoid extinction of populations of the focal species (IUCN 2013). They have become a critical tool in the conservation of many endemic fauna around the world as invasive species and anthropogenic influences continue to affect their survivorship. The motivations for assisted colonisation are varied; however, their success or failure is determined through 3 key criteria: (1) the initial survival of

${ }^{*}$ Corresponding author: anthony.rendall1@gmail.com the release group, (2) successful breeding by the release group and their offspring and (3) persistence of the established population (Seddon 1999). In each case, the outcome is influenced by several factors including presence of feral predators, release habitats (Sheean et al. 2012) and captive naivety (Mathews et al. 2005). Habitat suitability is even more pertinent when considering the assisted colonisation of a species to a region outside of its indigenous range.

Assisted colonisations are increasingly being used for endangered species where key threatening processes cannot be mitigated within their indigenous

(C) The authors 2018. Open Access under Creative Commons by Attribution Licence. Use, distribution and reproduction are unrestricted. Authors and original publication must be credited. 
range. Islands provide ideal locations for assisted colonisations with an increased ability to successfully eradicate invasive species in these ecosystems (Phillips 2010). In Australasia, predator-free islands have enabled the establishment of several species, including the golden bandicoot Isoodon auratus (Ottewell et al. 2014), Tasmanian devil Sarcophilus harrisii (Thalmann et al. 2016), western barred bandicoots Perameles bougainville (Short et al. 1998) and the kakapo Strigops habroptilus (Lloyd \& Powlesland 1994). Although success has been achieved (Fischer \& Lindenmayer 2000), failures highlight the need to understand the factors that enable or prevent these populations from successfully establishing within new environments (Kemp et al. 2015).

Selection of release sites is a critical component of any reintroduction but can be difficult to identify for threatened species with reduced ranges. Habitat suitability for threatened species is often gauged by habitat use within restricted or relic populations that may inhabit sub-optimal regions at the peripheries of their indigenous range (Osborne \& Seddon 2012). Given the importance of release site suitability, understanding habitat use immediately post-release when founders are adjusting to new environmental conditions may improve the success rate of future assisted colonisations.

The eastern barred bandicoot Perameles gunnii (mainland form, un-named sub-species) was once widespread throughout the tussock grasslands of western Victoria from the South Australian border to Melbourne's western suburbs (Seebeck 1979). Since European settlement, the species has undergone a significant reduction in its range, largely attributable to habitat loss and predation by the introduced red fox Vulpes vulpes (Seebeck 1979). Such population pressures have resulted in the species being listed as endangered under the Commonwealth Environmental Protection and Biodiversity Conservation Act 1999 and as extinct in the wild by the Victorian Department of Environment, Land, Water and Planning's (DELWP) Advisory List of Threatened Vertebrate Fauna (Department of Sustainability and Environment 2013). In an attempt to re-establish viable populations, reintroductions at 9 locations within the indigenous range have been attempted with varying levels of success (Winnard \& Coulson 2008). Predation by red foxes $V$. vulpes is the primary reason for reintroduction failure, a problem exacerbated by poor quality habitat and drought (Todd et al. 2002, Winnard \& Coulson 2008). Studies of habitat use within the indigenous range have shown that bandicoots require a mix of structurally complex habitats for nesting and open habitats for foraging (Dufty 1994, Cook et al. 2010, Winnard et al. 2013).

In 2015, eastern barred bandicoots persisted across 5 geographically isolated populations (Parrott et al. 2017) ranging in size from $~ 60$ individuals in the captive insurance population to around 1000 individuals at Mt. Rothwell (D. Sutherland unpubl. data), with all bandicoots, from all sites, being descendants of 19 founder individuals (Weeks et al. 2013). In 2010, genetic diversity in the remaining mainland bandicoot population had dropped by 35 to $40 \%$ from the level in 1990. To prevent further loss of diversity, a rapid population increase to 2500 individuals is required (Hill et al. 2010). To achieve this, the Eastern Barred Bandicoot Recovery Team has initiated projects to establish the species on fox-free islands, where threats can be managed effectively (Coetsee 2016, Hill et al. 2018).

In this study, we aimed to assess the survival and habitat use of bandicoots immediately post-release in a novel environment to help inform future assisted colonisations of the species. Specifically, we aimed to quantify habitat use through assessment of the importance of structurally complex habitats, how habitat use changed over the first $30 \mathrm{~d}$ post-release and whether there were sex- or origin-based differences.

\section{MATERIALS AND METHODS}

\section{Study species and location}

Eastern barred bandicoots (hereafter 'bandicoots') are small marsupials, with adults weighing from 600 to $1000 \mathrm{~g}$. Bandicoots typically live 2 to $3 \mathrm{yr}$ and can produce up to 5 litters of 1 to 4 young $\mathrm{yr}^{-1}$, if conditions allow (Dufty 1995). They are strictly nocturnal, nesting during the day in leaf litter or grass-lined nests hidden in a small scrape usually within structurally complex habitats, then emerging at night to forage in open habitats (Dufty 1991, Winnard et al. 2013). Their diet consists largely of invertebrates on or under the soil surface such as earthworms, various beetle larvae (coleopteran and lepidopteran) and adults (Coleoptera), as well as vegetative material including grass and roots (Reimer \& Hindell 1996).

Churchill Island $\left(38^{\circ} 29^{\prime} 59^{\prime \prime} \mathrm{S}, 145^{\circ} 20^{\prime} 19^{\prime \prime} \mathrm{E}\right)$ is 52 ha in size, $91 \mathrm{~km}$ south-east of Melbourne beyond the indigenous range of the species (Fig. 1). Churchill Island sits off the northern coastline of Phillip Island and is connected by a $100 \mathrm{~m}$ concrete bridge. Biosecurity measures are in place to prevent incursions of introduced red foxes, feral cats and rabbits Oryctola- 

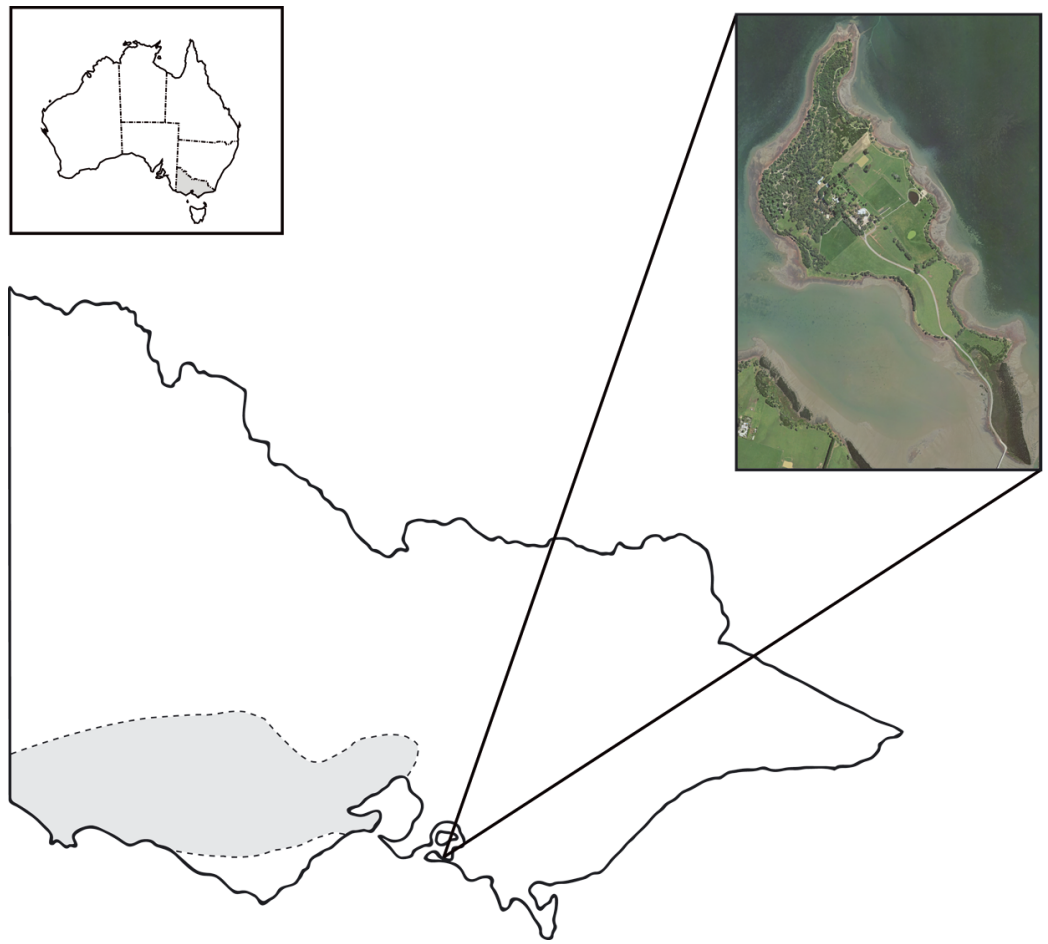

Fig. 1. Outline of Victoria, Australia, with historical eastern barred bandicoot distribution shown in grey. Zoomed-in aerial view illustrates the broad habitat types of Churchill Island within Victoria

gus cuniculus, including intense fox control (Kirkwood et al. 2014, Rout et al. 2014) and a predatorresistant gate that is shut from dusk to dawn. Twothirds of the island is operated as a heritage farm with grazing sheep, cattle and horses, while the remainder of the island supports regenerating bushland consisting of swamp paperbark Melaleuca ericifolia, eucalyptus Eucalyptus globulus and moonah Melaleuca lanceolata ssp. lanceolata shrublands. The understorey is dominated by introduced pasture grasses with coastal tussock-grasses Poa labillardierei var. labillardierei, blue tussock grass Poa poiformis and seaberry saltbush Ragodia candolleana ssp. candolleana scattered throughout. In this study, habitat was characterised into 4 broad types: tea tree woodlands (thick swamp paperbark with an open understorey); coastal mixed woodlands (sparse moonah woodlands, with a mixed understorey of tussock grass and seaberry saltbush); mixed woodlands (mature eucalyptus and immature moonah woodlands, with a variable understorey of tussock grass and unmanicured pasture grass); and pasture (pasture grass).

Churchill Island was chosen as the release site for bandicoots due to the absence of introduced pest species and the presence of woodland and open pasture considered suitable for bandicoots, as it provides habitat for both nesting and foraging (Dufty 1994, Winnard \& Coulson 2008). Native predators including the eastern barn owl Tyto javanica and the southern boobook Ninox boobook are both known to occur on the island and surrounding landscape.

\section{The release}

A total of 16 bandicoots were translocated to Churchill Island on $16 \mathrm{Au}-$ gust 2015. Eight came from Zoos Victoria's captive-breeding program, and a further 8 were translocated from the free-ranging population at $\mathrm{Mt}$. Rothwell Biodiversity Interpretation Centre near Lara $\left(3^{\circ} 53^{\prime} 41.68^{\prime \prime} \mathrm{S}\right.$, $\left.144^{\circ} 26^{\prime} 18.35^{\prime \prime} \mathrm{E}\right)$, a grassy woodland reserve with basaltic stony rises surrounded by a predator barrier fence (see Winnard et al. 2013). An equal sex ratio was taken from each source population. Free-ranging bandicoots were captured the evening prior to release and all animals were transported to the release site on the day of release. Bandicoots were hard released (de Milliano et al. 2016) after dusk at the interface between either tea tree woodlands or mixed woodlands (i.e. structurally complex habitats) and pasture.

\section{Health assessments}

Bandicoots were live-trapped 2 and 4 weeks postrelease to assess health and body condition. Wire cage traps (length $\times$ width $\times$ height: $50 \times 18 \times 20 \mathrm{~cm}$ ) baited with a mix of rolled oats, peanut butter and golden syrup were placed around bandicoot nesting locations and in nearby foraging areas, and deployed for 4 consecutive nights. Captured bandicoots were weighed and their physical condition assessed. Females' pouches were checked for pouch young and their respective developmental stage recorded.

\section{Radio tracking}

Each bandicoot was fitted with a $2.5 \mathrm{~g}$ transmitter with a $120 \mathrm{~mm}$ whip antenna mounted on cable-tie collars (Coetsee et al. 2016). Individuals were tracked 
using a yagi antenna (Sirtrack) and receiver (R1000, Communication Specialists). Locations of animals active at night were determined each night for up to $30 \mathrm{~d}$. Where possible, each bandicoot was observed each evening to verify that movements were unimpeded by the collar (as this was the first test of the collar on free-ranging bandicoots); when bandicoots were in dense vegetation, locations were estimated by in-field triangulation. All triangulations were across short distances, meaning we could confidently assign locations to habitats used. Each bandicoot was located once per night to ensure independence of fix locations. The order of individuals in which fixes were taken differed nightly to reduce any temporal bias. Nest site locations were determined each day for $1 \mathrm{wk}$ post-release and approximately twiceweekly thereafter. Plant species under which bandicoots nested were recorded for each location. All locations were taken using a Hemisphere R110 differential GPS $( \pm 0.5 \mathrm{~m})$, and the activity (nesting, foraging) of the individual was recorded. All collars were removed $30 \mathrm{~d}$ post-release in response to welfare concerns for collared bandicoots as a result of a bandicoot being detected with a foreleg entangled in the collar.

\section{Statistical analysis}

Home range size

Home range size and utilisation distributions for each individual were calculated using kernel estimators. Initially, smoothing parameters were not able to be minimised through least squares cross validation due to the presence of multiple identical relocations (i.e. repeated use of the same nest site). This is a known problem with kernel estimators; therefore, we removed repeated diurnal nesting locations $(n=68$, mean $=4.25$, median $=4$ ) from the data (Calenge 2011). A fixed kernel with least squares cross validation was used to determine the smoothing parameter for each individual. Over-smoothing was observed for some individuals (Kernohan et al. 2001); to ensure consistency, the same smoothing parameter was used for each individual. The largest smoothing parameter generated through least squares cross validation was applied to all individuals. This ensured that consistent smoothing parameters were applied throughout, while preventing over-smoothing of these data. Incremental area analysis was conducted to determine whether our estimates were likely to be reflective of the individuals' overall range. Minimum con- vex polygons (95\%) were also calculated to enable comparison with prior studies on the same species (Ferguson 2006, Winnard et al. 2013, Groenewegen et al. 2017).

The level of spatial overlap between individuals (male-male; female-female; male-female) was determined with the use of Bhattacharyya's affinity (BA). BA reflects the level of overlap between 2 individuals' home ranges on a scale from 0 to 1 , where $\mathrm{BA}=0$ indicates no overlap and $\mathrm{BA}=1$ indicates complete overlap. This statistic has been shown to perform best for home range overlap analysis if the aim is to quantify the overall similarity between 2 utilisation distributions (Fieberg \& Kochanny 2005).

\section{Habitat selection}

Nocturnal habitat selection was determined for all individuals for which a utilisation distribution could be calculated $(n=15)$. An Eigen-analysis of selection ratios for design II studies was conducted to explore habitat selection by bandicoots (Calenge \& Dufour 2006). The Eigen-analysis is a non-centred and nonscaled principal component analysis that compares the availability of each habitat to the habitats used by particular individuals (i.e. selection ratios). Design II studies distinguish between individuals, but assume that habitat availability is the same for all animals. Churchill Island was classified into 4 broad habitat types: tea tree woodlands; coastal mixed woodlands; mixed woodlands; and pasture. These classifications were selected to reflect habitats that have been identified as important in previous studies (Dufty 1994, Mallick et al. 1997), with the addition of coastal environments.

\section{Change in habitat use through time}

Habitat structural complexity was determined for each bandicoot location from LiDAR point cloud data collected in 2008. A digital elevation model (DEM) and a digital surface model (DSM) were generated representing the ground/topography and the highest point above ground (i.e. tree canopy, building roof) respectively. The DSM was subtracted from the DEM to produce a layer of habitat structure at a $1 \mathrm{~m}^{2}$ resolution. Visual inspection of these data revealed that a section of tea tree had become established since the 2008 LiDAR data was produced. Therefore, pixel values of regions now with tea trees were isolated from recent (2015) air photos (10 cm resolution) and values 
increased to more accurately reflect the vegetative structure of Churchill Island at the time of the study. Bandicoot locations were buffered to $10 \mathrm{~m}$, with the average height of vegetation within each buffer zone used to reflect the structural complexity of each bandicoot relocation. This measure of structural complexity has limitations in that tall overstorey with sparse understorey will be considered complex habitat; however, this is a more generalisable metric of habitat, with ground truthing supporting it as a reasonable measure of complexity.

Generalised linear mixed models (GLMMs) were used to identify potential habitat and temporal parameters driving habitat use by bandicoots. Where residual plots suggested non-linear relationships, generalised additive mixed models (GAMMs) were used. Candidate models were created to test (1) whether bandicoots increased their distance travelled over time and (2) whether the structural complexity of habitat used by bandicoots changed over time. Differences between the sexes and origin (captive or free-ranging) were considered in each model, with interactions between sex and days since release and origin and days since release included to allow for changes in habitat use by one sex or origin to vary independently of the other. Nocturnal (foraging) and diurnal (nesting) fixes were analysed in separate models. Bandicoot identity was included as a random factor in all models to account for the innate dependency between locations for the same individual. Models were run with either an underlying Poisson or Gaussian distribution, based on visual inspection of the data. Where over-dispersion was detected within the data, a negative binomial distribution was used. Colinearity between explanatory covariates was assessed within each model. Only covariates with a Pearson correlation coefficient $<0.4$ were included within the same model. Residual plots of observed versus fitted values, and fitted values compared to each parameter within the model were used to validate each model. A fixed variance structure was applied to the GLMM of nocturnal distance from first nest to account for heterogeneity patterns in the residuals. Once validated, Akaike's information criterion corrected for small sample sizes $\left(\mathrm{AIC}_{\mathrm{c}}\right)$ was used to determine the most parsimonious model.

All analyses were run in R ( $\mathrm{R}$ Development Core Team 2017), with home range and utilisation distributions calculated through 'adehabitatHR' and habitat selection analysis conducted within 'adehabitatHS' (Calenge 2006). GLMMs were run in 'mgcv' (Wood 2011) or 'lme4' (Bates et al. 2015) and GAMMs in 'gamm4' (Wood \& Scheipl 2014). Model selection was performed with 'AICcmodavg' (Mazerolle 2016) and R-squared values calculated in 'MuMIn' (Barton 2016). Habitat categories were created and manipulated in QGIS 2.10.1-Pisa (QGIS Development Team 2016) at a scale of 1:500. Habitat structural complexity was calculated from LiDAR data collected using a Leica ALS50 sensor with a vertical accuracy of $0.1 \mathrm{~m}$ with DEMs and DSMs created in ArcGIS 10.1 (ESRI 2012).

\section{RESULTS}

\section{Survival}

The survival rate of founding individuals was $94 \%$ after $1 \mathrm{mo}$. Three females were translocated from Mt. Rothwell carrying two $\leq 25$ d old unfurred pouch young each; all pouch young survived the translocation process. One death of a captive-raised bandicoot occurred $7 \mathrm{~d}$ after the initial release. The individual was considered to have been unable to adapt to the wild; an autopsy revealed severe dehydration and emaciation, with no food observed within the stomach and a $30 \%$ reduction in body weight since release. The majority of individuals gained weight throughout the first month, with breeding observed in the field and pouch young conceived on Churchill Island detected within $4 \mathrm{wk}$ of release.

\section{Radio tracking}

A total of 500 location fixes were collected from 16 bandicoots. Of these, 185 were diurnal nesting locations and 315 nocturnal fixes (foraging $n=204$; moving $\mathrm{n}=111$ ). A total of 15 bandicoots had a minimum of 24 fixes (mean $=27$ ) that were used for home range analyses (males $\mathrm{n}=8$; females $\mathrm{n}=7$ ). Males were found to have larger home ranges $(95 \%$ utilisation distribution [UD], a smoothing parameter: mean = $19.5 \mathrm{ha}$; range: 16.6 to $23.1 ; \mathrm{h}=40.1$ ) than females $($ mean $=9.0$ ha, range: 5.6 to $15.24 ; \mathrm{h}=40.1)($ Table 1). Females showed less spatial overlap $(B A=0.17)$ than did males $(\mathrm{BA}=0.47)$, while male and female home ranges showed some overlap $(\mathrm{BA}=0.36)$.

\section{Habitat selection}

Bandicoots nested within a wide range of vegetation classes (Fig. 2). Habitats dominated by native tussock grasses were the most commonly used nest- 
Table 1. Demographic and home range data for released eastern barred bandicoots on Churchill Island. Bandicoot release weight, minimum convex polygons (MCP) and utilisation distributions (UD) are presented (means \pm SD). Asymptote signifies whether sufficient data were collected to provide a fully representative UD; presented as proportion of home ranges that reached an asymptote, versus those that did not. Calculations were not made for 1 bandicoot due to a limited number of locations obtained $(n=13)$ of which few were active fixes $(n=6)$

\begin{tabular}{|lccccc|}
\hline Source population & Sex & Release weight $(\mathrm{g})$ & 95\% MCP (ha) & 95\% UD (ha) & Asymptote \\
\hline Captive & Female & $612.5 \pm 40.3$ & $4.09 \pm 3.37$ & $10.37 \pm 4.32$ & $0 / 3$ \\
Captive & Male & $741.8 \pm 100.6$ & $8.57 \pm 0.98$ & $18.58 \pm 1.34$ & $2 / 4$ \\
Free-ranging & Female & $595.3 \pm 81.1$ & $1.33 \pm 1.24$ & $11.95 \pm 2.44$ & $2 / 4$ \\
Free-ranging & Male & $584.0 \pm 59.2$ & $17.26 \pm 11.27$ & $20.43 \pm 2.81$ & \\
a Three females were carrying 2 pouch young each & & & \\
\hline
\end{tabular}

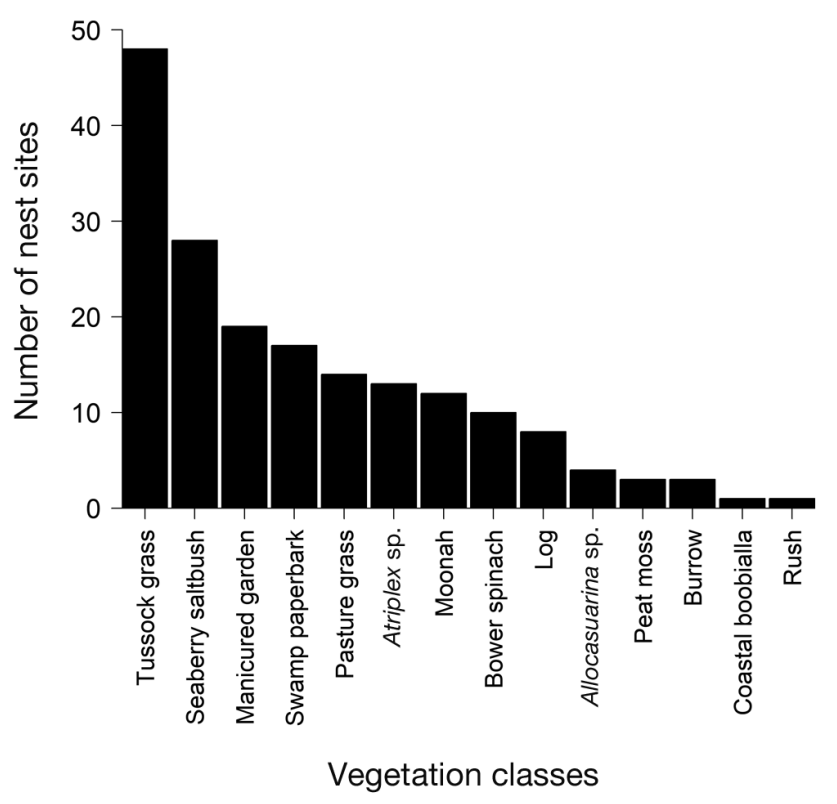

Fig. 2. Nest site selection of eastern barred bandicoots across $30 \mathrm{~d}$ immediately post-release on Churchill Island, Victoria

ing sites (either blue tussock grass or coastal tussock grass) followed by seaberry saltbush Rhagodia candolleana. Nests were found in more structurally complex habitats with leaf litter used for nest construction at the base of trees (moonah, swamp paperbark, Allocasuarina sp.) or under dense ground-storey vegetation (tussock grass, seaberry saltbush and Atriplex sp.). Bandicoots also opportunistically used logs, burrows and ornamental shrubs in managed gardens as nest sites.

Bandicoots foraging at night were found to use particular habitats more than were available. However, the habitats that were used differed between individuals. Female bandicoots utilised coastal woodlands more than expected, while individuals sourced from free-ranging populations used a wider variety of available habitats (Fig. 3). Several bandicoots used the coastal boundary of the island more than was expected, with 2 female free-ranging bandicoots heavily selecting for this habitat (Fig. 3). Only one individual, a female free-ranging bandicoot, used pasture more than was available. Some bandicoots selected a mosaic of habitat types and were found to use them similarly to their availability, particularly a captive female who frequently used high structure mixed woodlands and coastal woodlands (Fig. 3).

\section{Change in habitat use through time: distance to first nest}

The global model of nocturnal fixes including time since release, sex, origin and both 2-way interaction terms was found to be strongly supported by the data (Table 2). Bandicoots increased the distance travelled between their first nest and foraging sites over time, with shorter distances travelled immediately post-release and larger movements travelled as time since release increased. Males travelled considerably further than females (Fig. 4). Whether individuals were from a captive population or free-ranging population also influenced their distance moved, with free-ranging individuals travelling further than captive individuals (Fig. 5).

The best supported model of diurnal fixes included time since release with a smoothing parameter and origin of individual (Table 2). Over time, bandicoots moved further away from their first nest, with captive individuals moving greater distances between nest sites than free-ranging individuals (Fig. 6). Neither sex nor the interaction between sex and time since release were present in the top models, suggesting there was limited support for a difference between sexes in the distance moved from first nest. 


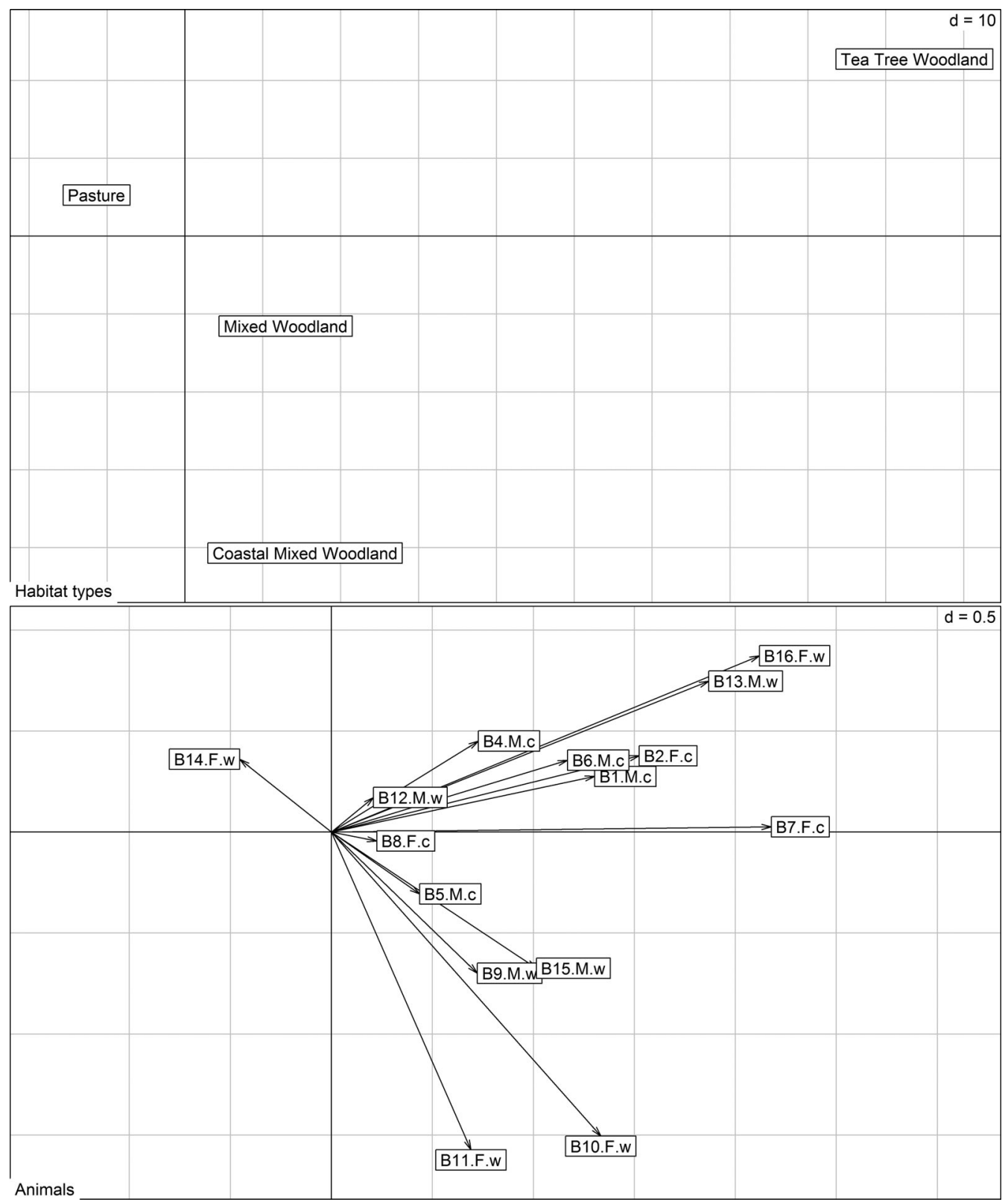

Fig. 3. Eigen-analysis of selection ratios representing the primary habitats selected by eastern barred bandicoots during nocturnal foraging. Top panel represents available habitats; bottom panel demonstrates how closely related individual bandicoots were to particular habitats. The more a bandicoot location overlaps with a habitat type, the more exclusively this habitat was used by that individual. Where bandicoot locations fall between 2 habitats, the individual used both habitat types. Labels represent whether the bandicoot was male $(\mathrm{M})$ or female $(\mathrm{F})$, and whether they were from captive (c) or free-ranging (w) populations

\section{Change in habitat use through time: habitat structural complexity}

There was considerable model selection uncertainty, with the top 3 models receiving $\mathrm{AIC}_{\mathrm{c}}$ scores $<2$ and with all models explaining $<8 \%$ of variation within these data (Table 2). The poor explanatory power of these models suggests that structural complexity of habitat may have a limited relationship with bandicoot activity. Our results do suggest that, while bandiroots were active, low structurally complex habitats were used more frequently as time since released increased; and free-ranging bandicoots used open habitats more than captive individuals. 
Table 2. Models considered to describe nocturnal and diurnal habitat use by eastern barred bandicoots in relation to their use of habitat structural complexity and the change in distances moved from nest locations to foraging sites. Models are ranked based on Akaike's information criteria corrected for small sample sizes $\left(\mathrm{AIC}_{\mathrm{c}}\right)$. Reported are the number of parameters within the model (K), the difference from the model with lowest $\mathrm{AIC}_{\mathrm{c}}\left(\Delta \mathrm{AIC} \mathrm{C}_{\mathrm{c}}\right)$, model $\mathrm{AIC}_{\mathrm{c}}$ weights $\left(\mathrm{AIC}_{\mathrm{c}} \omega\right)$ and adjusted R-squared values $\left(\mathrm{R}^{2}\right)$. Model parameters include distance to first nest (Dist), structural complexity of habitat (Struc), time since release (TSR), whether an individual was from a captive or free-ranging population (Origin), and constant model (1); $\mathrm{s}(x)$ indicates where a smoothing parameter has been applied. GLMM: generalised linear mixed model; GAMM: generalised additive mixed model

\begin{tabular}{|c|c|c|c|c|c|c|c|}
\hline Model & Type & Model formula & $\mathrm{K}$ & $\mathrm{AIC}_{\mathrm{c}}$ & $\Delta \mathrm{AIC}_{\mathrm{c}}$ & $\mathrm{AIC}_{\mathrm{c}} \omega$ & $\mathrm{R}^{2}$ \\
\hline $\begin{array}{l}\text { Distance to first } \\
\text { nest: nocturnal }\end{array}$ & GLMM & $\begin{array}{l}\text { Dist }=\mathrm{TSR}+\mathrm{Sex}+\text { Origin }+\mathrm{TSR} \times \mathrm{Sex}+\mathrm{TSR} \times \text { Origin } \\
\text { Dist }=\mathrm{TSR}+\mathrm{Sex}+\text { Origin }+\mathrm{TSR} \times \mathrm{Sex}\end{array}$ & $\begin{array}{l}8 \\
7\end{array}$ & $\begin{array}{l}3899.71 \\
3913.44\end{array}$ & $\begin{array}{r}0.00 \\
13.73\end{array}$ & $\begin{array}{l}1 \\
0\end{array}$ & $\begin{array}{l}0.409 \\
0.298\end{array}$ \\
\hline $\begin{array}{l}\text { Distance to first } \\
\text { nest: diurnal }\end{array}$ & GAMM & $\begin{array}{l}\text { Dist }=\mathrm{s}(\mathrm{TSR})+\text { Origin } \\
\text { Dist }=\mathrm{s}(\mathrm{TSR}, \text { by Origin })+\text { Origin } \\
\text { Dist }=\mathrm{s}(\mathrm{TSR}) \\
\text { Dist }=\mathrm{s}(\mathrm{TSR})+\text { Sex } \\
\text { Dist }=\mathrm{s}(\mathrm{TSR}, \text { by Sex })+\text { Sex }\end{array}$ & $\begin{array}{l}6 \\
8 \\
5 \\
6 \\
8\end{array}$ & $\begin{array}{l}1772.85 \\
1776.68 \\
1777.14 \\
1778.83 \\
1782.23\end{array}$ & $\begin{array}{l}0.00 \\
3.83 \\
4.29 \\
5.98 \\
9.38\end{array}$ & $\begin{array}{l}0.76 \\
0.11 \\
0.09 \\
0.04 \\
0.01\end{array}$ & $\begin{array}{l}0.172 \\
0.198 \\
0.093 \\
0.107 \\
0.127\end{array}$ \\
\hline $\begin{array}{l}\text { Use of structure: } \\
\text { nocturnal }\end{array}$ & GLMM & $\begin{array}{l}\text { Struc }=\mathrm{TSR}+\text { Origin }+\mathrm{TSR} \times \text { Origin } \\
\text { Struc }=\mathrm{TSR}+\text { Origin } \\
\text { Struc }=\mathrm{TSR}+\mathrm{Sex}+\text { Origin }+\mathrm{TSR} \times \text { Origin } \\
\text { Struc }=\mathrm{TSR}+\mathrm{Sex}+\text { Origin }+\mathrm{TSR} \times \text { Origin }+\mathrm{TSR} \times \mathrm{Sex}\end{array}$ & $\begin{array}{l}6 \\
5 \\
7 \\
8\end{array}$ & $\begin{array}{l}1230.53 \\
1231.13 \\
1231.92 \\
1233.61\end{array}$ & $\begin{array}{l}0.00 \\
0.59 \\
1.39 \\
3.08\end{array}$ & $\begin{array}{l}0.41 \\
0.30 \\
0.20 \\
0.09\end{array}$ & $\begin{array}{l}0.071 \\
0.062 \\
0.073 \\
0.074\end{array}$ \\
\hline $\begin{array}{l}\text { Use of structure: } \\
\text { diurnal }\end{array}$ & GLMM & $\begin{array}{l}\text { Struc }=\mathrm{TSR}+\mathrm{Sex}+\text { Origin }+\mathrm{TSR} \times \mathrm{Sex} \\
\text { Struc }=\mathrm{TSR}+\mathrm{Sex}+\mathrm{TSR} \times \mathrm{Sex} \\
\text { Struc }=\mathrm{TSR}+\mathrm{Sex}+\text { Origin }+\mathrm{TSR} \times \text { Origin }+\mathrm{TSR} \times \mathrm{Sex}\end{array}$ & $\begin{array}{l}6 \\
5 \\
7\end{array}$ & $\begin{array}{l}673.40 \\
674.31 \\
675.56\end{array}$ & $\begin{array}{l}0.00 \\
0.91 \\
2.16\end{array}$ & $\begin{array}{l}0.51 \\
0.32 \\
0.17\end{array}$ & $\begin{array}{l}0.212 \\
0.130 \\
0.211\end{array}$ \\
\hline
\end{tabular}

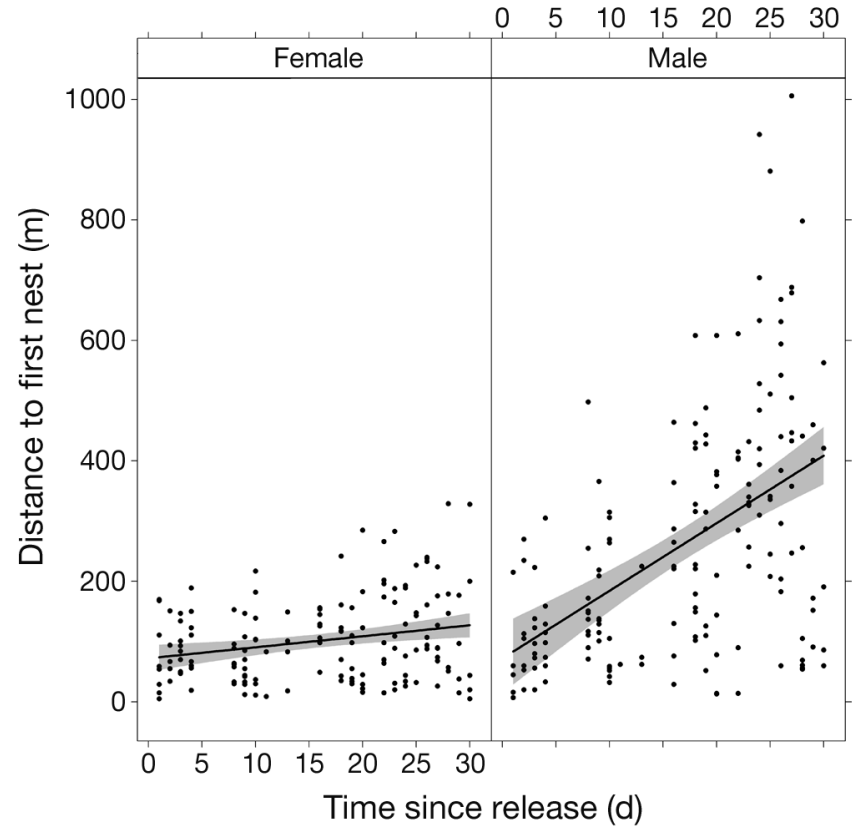

Fig. 4. Relationship between time since release of eastern barred bandicoots and the nocturnal distances moved from their first nest after translocation for each sex

The structural complexity of habitats used while nesting was associated with time since release, sex, origin and an interaction term between time since release and sex. However, there was model selection uncertainty (Table 2). Females initially used more structurally complex habitats using lower structure

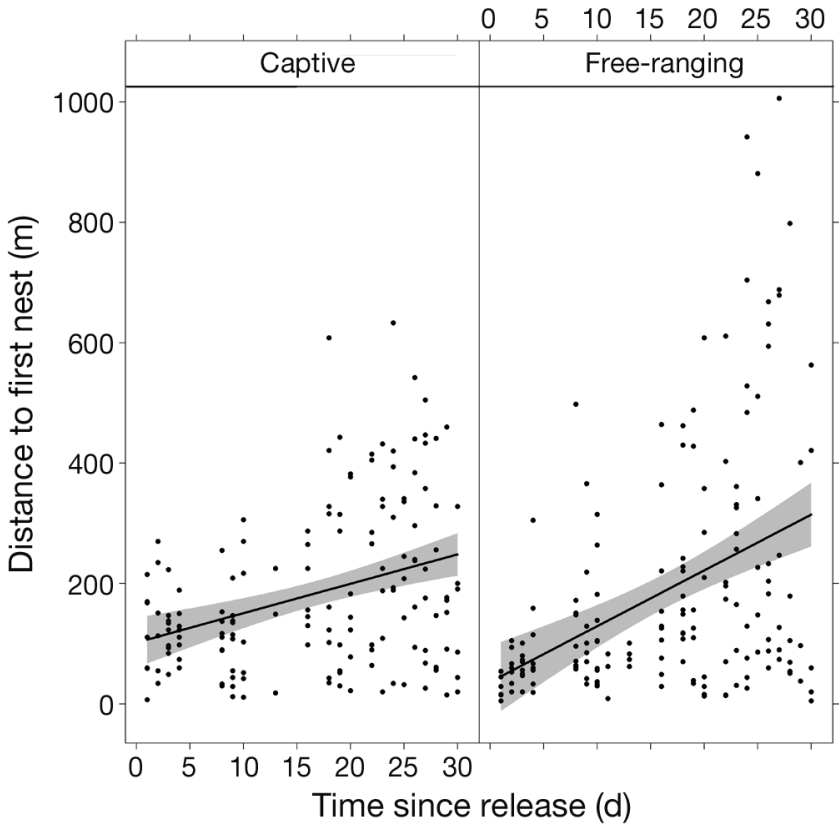

Fig. 5. Relationship between time since release of eastern barred bandicoots and the nocturnal distances moved from their first nest after translocation dependent on whether the individual was from a captive or free-ranging population

for nesting through time, whereas males initially used lower structural complexity using more complex nesting sites through time (Fig. 7). Despite these shifts, bandicoots were not found to use nest sites with less than $1 \mathrm{~m}$ of structural complexity on average. Origin of individuals had a weak relationship 


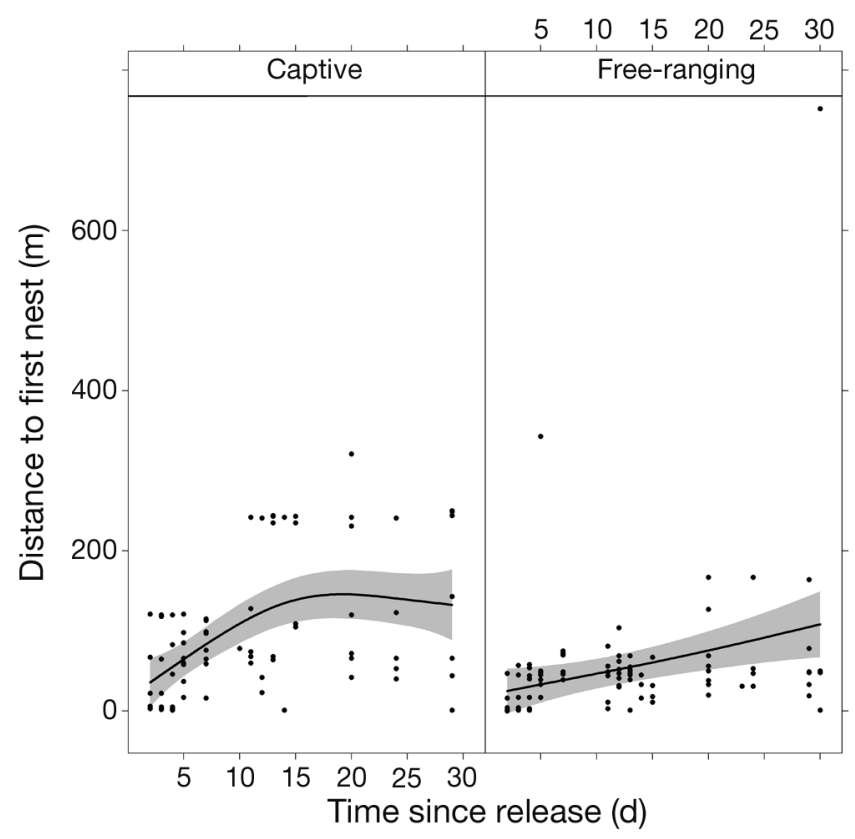

Fig. 6. Relationship between time since release of eastern barred bandicoots and the diurnal distances moved from their first nest after translocation dependent on whether the individual was from a captive or free-ranging population

with vegetation complexity, with free-ranging individuals suggested to use less structurally complex habitats as time since release increased. This trend had limited power to explain the variation within the data (Table 2).

\section{DISCUSSION}

Assisted colonisations are a valuable conservation tool; however, limited research has focused on the factors that enable or prevent their success. Here, we demonstrated how monitoring habitat use postrelease can provide important information required to inform and potentially improve the success of future assisted colonisations. Bandicoots were found to initially use more structurally complex habitats for both nesting and foraging than available, a result potentially influenced by their release locations. However, as they became more established within their new environment they expanded their movements from their point of release. Males in particular moved further between their nesting and foraging sites and started using less structurally complex habitats. This trend supports the findings of studies in more established populations, where individuals showed a willingness to forage exclusively in less structurally complex habitats (Winnard et al. 2013).

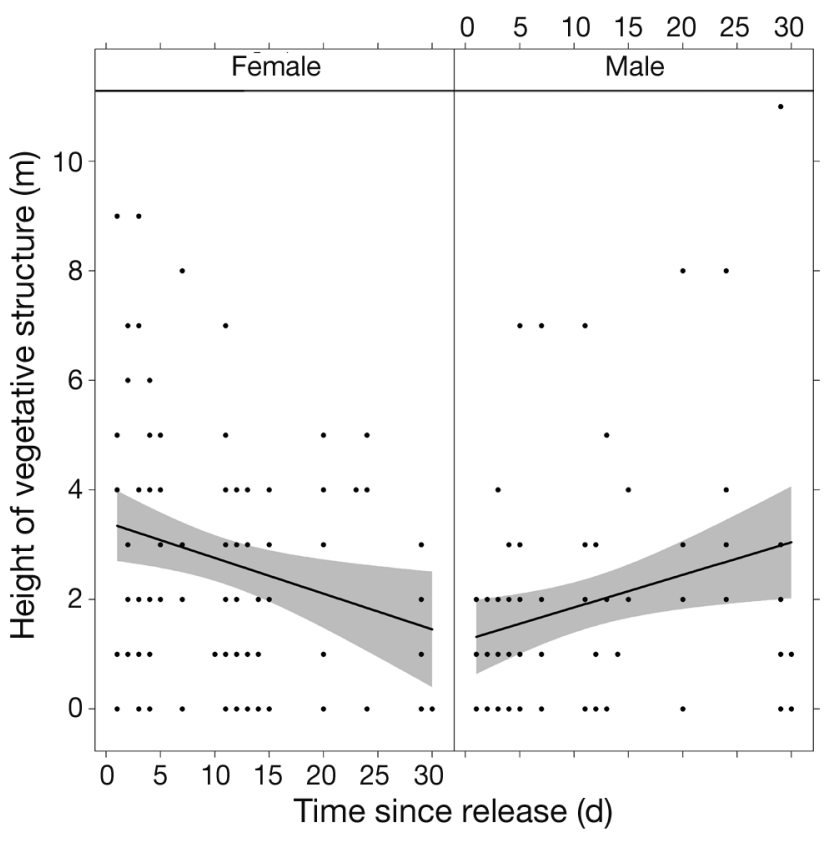

Fig. 7. Height of habitat structural complexity within a $10 \mathrm{~m}$ radius of eastern barred bandicoot nesting locations in relation to time since release and bandicoot sex

The initial use of structurally complex habitats and limited range expansion has been observed before (Winnard 2010) and may provide individuals with greater protection from potential predators. This is an important consideration for future assisted colonisations to islands where invasive predators such as feral cats are not able to be eradicated. Studies in the presence of invasive predators suggested an absence of structurally complex habitat may have limited bandicoot distributions (Brown \& Seebeck 1989). Research has also highlighted how invasive predators can be less successful when foraging within more complex habitats (McGregor et al. 2015); as such, releasing individuals into structurally complex habitats may provide greater survival in the presence of predators.

The origin of individual bandicoots was found to influence how they used habitat on release. Freeranging individuals sourced from Mt. Rothwell, a 420 ha predator-proof fenced enclosure, moved greater distances and used less structurally complex habitats than those sourced from Zoos Victoria's captive breeding program. This may reflect less habitat awareness of captive-bred individuals compared to free-ranging bandicoots. Studies of captive-bred versus wild individuals have found evidence of maladaptation in captive individuals, as they spend more time on unnecessary tasks and are less adapted to 
accessing wild food sources (Mathews et al. 2005). Captive-bred bandicoots, however, have regularly and successfully been used for reintroductions into their former range, and there appears to be no difference in their survival within the present study. The absence of cursorial predators on Churchill Island may have enabled higher survivorship irrespective of origin. Studies of burrowing bettongs Bettongia lesueur have demonstrated that wild translocated individuals were capable of altering their behaviour in the presence of a low density feral cat population (West et al. 2018). Future releases may need to consider the habitat awareness of captive and free-ranging individuals and how this might influence survival in the presence of invasive predators.

Habitat structural complexity was found to have an influence on bandicoot nest site selection; however, both males and females nested below vegetation of at least $1 \mathrm{~m}$ in height on average. Although shifts in male and female use of structural complexity for nesting were identified, this is likely a reflection of limited sample size and insufficient resolution within these data. Given the $10 \mathrm{~m}$ radius analysed here, nest site selection may be influenced on a smaller spatial scale. Bandicoot nocturnal habitat use throughout the study supports their initial use of structurally complex habitats and demonstrates their generalist nature, with all available habitat types used by different individuals. Similar results were found from suitability models where, despite a considerable range of vegetation types and species being modelled, none were found to be explanatory of bandicoot persistence at a site (Cook et al. 2010). The species has also been found to persist within degraded landscapes with limited vegetation due to over-grazing by macropods (Winnard et al. 2013). As a result, bandicoots are ideal candidates for assisted colonisations and are likely capable of occupying all available habitats on larger proposed islands (Coetsee 2016, Hill et al. 2018).

The home range sizes of released individuals are consistent with those of studies in more established populations. In the present study, male bandicoots had a mean home range of $19.5 \mathrm{ha}$; more than double that of females at 9.0 ha. Previous studies of established populations within a degraded landscape similarly found male ranges $(37.2 \mathrm{ha})$ to be double the size of female ranges (15.8 ha) (Winnard et al. 2013). The size of Churchill Island limits the space available to individuals, though not all of the island was used by males or females, suggesting range expansion was possible. This study is the first to be able to track all individuals simultaneously, something previously not possible due to issues with collar attachment (Coetsee et al. 2016). This revealed that females showed a lower level of home range overlap than males, suggesting territoriality between females. Intra-sexual territoriality has been observed in other marsupials including the spottedtailed quoll Dasyurus maculatus (Belcher \& Darrant 2004), chuditch Dasyurus geoffroii (Serena \& Soderquist 1989), northern quoll Dasyurus hallucatus (Oakwood 2002) and brush-tailed phascogale Phascogale tapoatafa (Soderquist 1995). Female territoriality has been associated with protection of food resources in microtine rodents (Ostfeld 1985). Such resource protection may provide areas for offspring to forage with reduced competition prior to dispersal from their natal home range. An alternative hypothesis is the offspring-defence hypothesis, which suggests that it may act as a preventative of infanticide from rival females (Wolff \& Peterson 1998). Infanticide was not observed, and has not been found for bandicoot species. It is considered rare in marsupials as most carry altricial young within their pouch. Intra-sexual territoriality within endangered species has implications for the management of their meta-populations. For eastern barred bandicoots there are currently 3 additional sites supporting bandicoots across Victoria (Hamilton Community Parklands, Mt. Rothwell and Woodlands Historic Park), with new sites under development (Coetsee 2016, Hill et al. 2018). However, as independent sites they are too small to halt a continued loss of genetic diversity (Weeks et al. 2013), hence these populations are managed as a single meta-population with adults introduced from the captive population into each site to increase genetic diversity (Hill et al. 2018). Given intra-sexual territoriality, females introduced into established populations may be outcompeted for space by conspecifics, limiting their chance to contribute to the genetics of the population. Males, on the other hand, may be more likely to successfully breed, yet may still experience intraspecific competition from rival males. One possible solution could be to introduce individuals as others are removed to contribute to new populations or the breeding program. In these circumstances, 'space' within the established population will become available for these new individuals to occupy. Determining the survival and breeding success of individuals introduced into established populations is a research priority.

Assisted colonisations into novel habitats are increasingly being used as a tool for conserving many endangered species (Seddon et al. 2015) when op- 
tions for release within their indigenous ranges are limited. Here, both male and female bandicoots remained close to their release sites for the first $2 \mathrm{wk}$ post-release. Future releases onto larger islands where invasive predators such as feral cats are present should consider release sites within more structurally complex habitats, less favourable to these predators, to improve survivorship of founding individuals. The ability to monitor 16 individuals simultaneously marks an improvement in our ability to monitor this species; however, problems with collar attachment did result in a reduced sample size, limiting our inferential power. Regardless, this study highlights the value of post-release monitoring in assisted colonisation campaigns and demonstrates how insights from monitoring can be used to inform and improve future colonisations.

Acknowledgements. This project was undertaken in accordance with the regulations of Phillip Island Nature Parks Animal Ethics committee under Project No. 3.2015 and in accordance with the Department of Environment, Land, Water and Planning (DELWP), Research Permit No. 10007613. Funding support was provided by Zoos Victoria. Thanks to Peter Dann for his work in establishing this project, and to Mt. Rothwell Biodiversity and Interpretation Centre, Zoos Victoria, DELWP and the members of the Eastern Barred Bandicoot Recovery Team, without whom this project would not have been possible. Thanks to Julian Di Stefano for comments on an earlier version of the manuscript. Finally, thanks also to the many volunteers who helped and provided assistance in the field.

\section{LITERATURE CITED}

Barton K (2016) MuMIn: multi-model inference. R package version 1.15.6. https://CRAN.R-project.org/package= MuMIn

Bates D, Maechler M, Bolker B, Walker S (2015) Fitting linear mixed-effects models using lme4. J Stat Softw 67: $1-48$

Belcher CA, Darrant JP (2004) Home range and spatial organization of the marsupial carnivore, Dasyurus maculatus maculatus (Marsupialia: Dasyuridae) in southeastern Australia. J Zool (Lond) 262:271-280

Brown PR, Seebeck JH (1989) Management plan for the conservation of the eastern barred bandicoot, Perameles gunnii, in Victoria: a report to the Department of Conservation, Forests, and Lands, Victoria and the World Wildlife Fund Australia. Arthur Rylah Institute for Environmental Research, Heidelberg

Calenge C (2006) The package 'adehabitat' for the R software: a tool for the analysis of space and habitat use by animals. Ecol Modell 197:516-519

Calenge C (2011) Home range estimation in R: the adehabitatHR package. $\mathrm{R}$ vignette:1-60

Calenge C, Dufour AB (2006) Eigenanalysis of selection ratios from animal radio-tracking data. Ecology 87: 2349-2355
Coetsee A (2016) Recovering the mainland eastern barred bandicoot. Vic Nat 133:98-103

Coetsee A, Harley D, Lynch M, Coulson G, de Milliano J, Cooper M, Groenewegen R (2016) Radio-transmitter attachment methods for monitoring the endangered eastern barred bandicoot (Perameles gunnii). Aust Mammal 38:221-231

Cook CN, Morgan DG, Marshall DJ (2010) Reevaluating suitable habitat for reintroductions: lessons learnt from the eastern barred bandicoot recovery program. Anim Conserv 13:184-195

* de Milliano J, Di Stefano J, Courtney P, Temple-Smith P, Coulson G (2016) Soft-release versus hard-release for reintroduction of an endangered species: an experimental comparison using eastern barred bandicoots (Perameles gunnii). Wildl Res 43:1-12

Department of Sustainability and Environment (2013) Advisory list of threatened vertebrate fauna in Victoria. Victoria Department of Sustainability and Environment, Melbourne

Dufty AC (1991) Some population characteristics of Perameles gunnii in Victoria. Wildl Res 18:355-366

WDufty A (1994) Habitat and spatial requirements of the eastern barred bandicoot (Perameles gunnii) at Hamilton, Victoria. Wildl Res 21:459-472

Dufty AC (1995) The growth and development of the eastern barred bandicoot Perameles gunnii in Victoria. Vic Nat 112:79-85

ESRI (2012) ArcGIS desktop: release 10.1. Environmental Systems Research Institute, Redlands, CA

Ferguson J (2006) Soft-release versus hard-release: the importance of acclimatisation to the initial success of reintroduced captive-bred eastern barred bandicoots. BSc (Hons) thesis, University of Melbourne

*Fieberg J, Kochanny CO (2005) Quantifying home-range overlap: the importance of the utilization distribution. J Wildl Manag 69:1346-1359

Fischer J, Lindenmayer DB (2000) An assessment of the published results of animal relocations. Biol Conserv 96: $1-11$

Groenewegen R, Harley D, Hill R, Coulson G (2017) Assisted colonisation trial of the eastern barred bandicoot (Perameles gunnii) to a fox-free island. Wildl Res 44:484-496 doi:10.1071/WR16198

Hill R, Watson M, Winnard A (2010) National recovery plan for the eastern barred bandicoot (mainland) Perameles gunnii unnamed subspecies. Department of Sustainability and Environment, Melbourne

Hill R, Coetsee A, Sutherland DR (2018) Recovery of the mainland subspecies of eastern barred bandicoot in Victoria. In: Garnett S, Latch P, Lindenmayer D, Woinarski JCZ (eds) Recovering Australian threatened species: a book of hope. CSIRO Publishing, Collingwood, p 249-258

IUCN (2013) Guidelines for reintroductions and other conservation translocations, version 1.0. IUCN Species Survival Commission, Gland

Kemp L, Norbury G, Groenewegen R, Comer S (2015) The roles of trials and experiments in fauna reintroduction programs. In: Armstrong DP, Hayward MW, Moro D, Seddon PJ (eds) Advances in reintroduction biology of Australian and New Zealand fauna. CSIRO Publishing, Collingwood, p 73-89

Kernohan BJ, Gitzen RA, Millspaugh JJ (2001) Analysis of animal space use and movements. In: Millspaugh JJ, 
Marzluff JM (eds) Radio tracking and animal populations. Academic Press, San Diego, CA, p 125-166

Kirkwood R, Sutherland DR, Murphy S, Dann P (2014) Lessons from long-term predator control: a case study with the red fox. Wildl Res 41:222-232

Lloyd BD, Powlesland R (1994) The decline of kakapo Strigops habroptilus and attempts at conservation by translocation. Biol Conserv 69:75-85

* Mallick SA, Hocking GJ, Driessen MM (1997) Habitat requirements of the eastern barred bandicoot, Perameles gunnii, on agricultural land in Tasmania. Wildl Res 24: 237-243

Mathews F, Orros M, McLaren G, Gelling M, Foster R (2005) Keeping fit on the ark: assessing the suitability of captive-bred animals for release. Biol Conserv 121:569-577

Mazerolle MJ (2016) AICcmodavg: model selection and multimodel inference based on (Q)AIC(c). R package version 2.1-1. https://cran.r-project.org/package=AICcmodavg

McGregor H, Legge S, Jones ME, Johnson CN (2015) Feral cats are better killers in open habitats, revealed by animal-borne video. PLOS ONE 10:e0133915

* Oakwood M (2002) Spatial and social organization of a carnivorous marsupial Dasyurus hallucatus (Marsupialia: Dasyuridae). J Zool (Lond) 257:237-248

Osborne PE, Seddon PJ (2012) Selecting suitable habitats for reintroductions: variation, change and the role of species distribution modelling. In: Ewen JG, Armstrong DP, Parker KA, Seddon PJ (eds) Reintroduction biology: integrating science and management. Blackwell Publishing, West Sussex, p 73-104

Ostfeld RS (1985) Limiting resources and territoriality in microtine rodents. Am Nat 126:1-15

Ottewell K, Dunlop J, Thomas N, Morris K, Coates D, Byrne M (2014) Evaluating success of translocations in maintaining genetic diversity in a threatened mammal. Biol Conserv 171:209-219

Parrott ML, Coetsee AL, Hartnett CM, Magrath MJL (2017) New hope for the eastern barred bandicoot Perameles gunnii after 27 years of recovery effort. Int Zoo Yearb 51: 154-164

Phillips RA (2010) Eradications of invasive mammals from islands: Why, where, how and what next? Emu 110:i-vii

QGIS Development Team (2016) QGIS geographic information system. Open Source Geospatial Foundation Project. http://qgis.osgeo.org

R Development Core Team (2017) R: a language and environment for statistical computing. R Foundation for Statistical Computing, Vienna

Reimer AB, Hindell MA (1996) Variation in body condition and diet of the eastern barred bandicoot (Perameles gunnii) during the breeding season. Aust Mammal 19:47-52

Rout TM, Kirkwood R, Sutherland DR, Murphy S, McCarthy MA (2014) When to declare successful eradication of an invasive predator? Anim Conserv 17:125-132

Seddon PJ (1999) Persistence without intervention: assessing success in wildlife reintroductions. Trends Ecol Evol $14: 503$

Editorial responsibility: Matt Hayward, Bangor, UK
Seddon PJ, Moro D, Mitchell NJ, Chauvenet al. Mawson PR (2015) Proactive conservation or planned invasion? Past, current and future use of assisted colonisation. In: Armstrong DP, Hayward MW, Moro D, Seddon PJ (eds) Advances in reintroduction biology of Australian and New Zealand fauna. CSIRO Publishing, Collingwood, p 105-126

Seebeck JH (1979) Status of the barred bandicoot, Perameles gunnii, in Victoria: with a note on husbandry of a captive colony. Aust Wildl Res 6:255-264

Serena M, Soderquist TR (1989) Spatial organization of a riparian population of the carnivorous marsupial Dasyurus geoffroii. J Zool (Lond) 219:373-383

Sheean VA, Manning AD, Lindenmayer DB (2012) An assessment of scientific approaches towards species relocations in Australia. Austral Ecol 37:204-215

Short J, Richards JD, Turner B (1998) Ecology of the western barred bandicoot (Perameles bougainville) (Marsupialia: Peramelidae) on Dorre and Bernier Islands, Western Australia. Wildl Res 25:567-586

K Soderquist TR (1995) Spatial organization of the arboreal carnivorous marsupial Phascogale tapoatafa. J Zool (Lond) 237:385-398

Thalmann S, Peck S, Wise P, Potts JM, Clarke J, Richley J (2016) Translocation of a top-order carnivore: tracking the initial survival, spatial movement, home-range establishment and habitat use of Tasmanian devils on Maria Island. Aust Mammal 38:68-79

Todd CR, Jenkins S, Bearlin AR (2002) Lessons about extinction and translocation: models for eastern barred bandicoots (Perameles gunnii) at Woodlands Historic Park, Victoria, Australia. Biol Conserv 106:211-223

*Weeks AR, Van Rooyen A, Mitrovski P, Heinze D, Winnard A, Miller AD (2013) A species in decline: genetic diversity and conservation of the Victorian eastern barred bandicoot, Perameles gunnii. Conserv Genet 14: 1243-1254

West R, Letnic M, Blumstein DT, Moseby KE (2018) Predator exposure improves anti-predator responses in a threatened mammal. J Appl Ecol 55:147-156

Winnard AL (2010) Reintroduction biology of the eastern barred bandicoot. PhD thesis, University of Melbourne

*Winnard AL, Coulson G (2008) Sixteen years of eastern barred bandicoot Perameles gunnii reintroductions in Victoria: a review. Pac Conserv Biol 14:34-53

*Winnard AL, Di Stefano J, Coulson G (2013) Habitat use of a critically-endangered species in a predator-free but degraded reserve in Australia. Wildl Biol 19:429-438

Wolff JO, Peterson JA (1998) An offspring-defense hypothesis for territoriality in female mammals. Ethol Ecol Evol 10:227-239

WWood SN (2011) Fast stable restricted maximum likelihood and marginal likelihood estimation of semiparametric generalized linear models. J R Stat Soc Series B Stat Methodol 73:3-36

*Wood S, Scheipl F (2014) gamm4: generalized additive mixed models using mgcv and $1 m e 4$. R package version 0.2-5. https://CRAN.R-project.org/package=gamm4

Submitted: December 19, 2017; Accepted: April 10, 2018

Proofs received from author(s): June 19, 2018 